\title{
Evaluasi Penerapan 'Inspekta', Aplikasi Berbasis Website Untuk Pelaporan Keselamatan Dan Kesehatan Kerja (K3) Di PLN UPDL Semarang
}

\author{
Tri Sakti Adiwibowo \\ PLN UPDL Semarang, PT PLN (Persero) Pusdiklat \\ t_sakti_tri@yahoo.com
}

\begin{abstract}
As an institution that is committed to implementing an Occupational Safety and Health Management System (SMK3) in accordance with Government Regulation Number 50 of 2012, the PLN Education and Training Implementation Unit (UPDL) Semarang continuously makes continuous improvements both to work processes, infrastructure, competence of personnel, work methods, and other resources that can support the achievement of Occupational Safety and Health (K3) performance and Company performance. One of the tools that can help smooth OSH monitoring and reporting activities at PLN is an information technology-based application called Inspekta. The purpose of this study is to determine and evaluate the use of information technology in relation to unsafe conditions, unsafe behavior (unsafe action), near misses, accidents and occupational diseases. The research method used in this research is observation, interviews and data analysis (documents). From the results of the research that has been done, it is found that the Inspecta application provides benefits in building awareness and monitoring as well as OHS reporting. The Inspekta application still needs to be optimized and developed again to make it more efficient and effective.
\end{abstract}

Keywords: Inspekta application, information technology, $K 3$

\begin{abstract}
Abstrak
Sebagai institusi yang memiliki komitmen untuk menerapkan Sistem Manajemen Keselamatan dan Kesehatan Kerja (SMK3) sesuai Peraturan Pemerintah Nomor 50 tahun 2012, PLN Unit Pelaksana Pendidikan dan Pelatihan (UPDL) Semarang secara terus menerus melakukan perbaikan (continuous improvement) baik terhadap proses kerja, infrastruktur, kompetensi personil, metode kerja, dan sumber-sumber daya lain yang dapat mendukung pencapaian kinerja Keselamatan dan Kesehatan Kerja (K3) maupun kinerja Perusahaan. Salah satu alat (tool) yang dapat membantu kelancaran kegiatan pemantauan dan pelaporan K3 di PLN adalah aplikasi berbasis teknologi informasi yang disebut Inspekta. Tujuan penelitian ini adalah untuk mengetahui dan mengevaluasi penggunaan teknologi informasi berkaitan dengan kondisi tidak aman (unsafe condition), perilaku tidak aman (unsafe action), kondisi hampir celaka (nearmiss), kecelakaan (accident) dan penyakit akibat kerja. Metode penelitian yang digunakan dalam penelitian ini adalah observasi, wawancara dan analisa data (dokumen). Dari hasil penelitian yang sudah dilakukan diperoleh hasil bahwa aplikasi inspekta memberi manfaat dalam membangun kepedulian dan pemantaun serta pelaporan K3. Aplikasi Inspekta masih perlu dioptimalkan dan dikembangkan lagi agar lebih berdaya guna dan berhasil guna.
\end{abstract}

Kata kunci: aplikasi inspekta, teknolgi informasi, K3 


\section{Energi dan Kelistrikan: Jurnal Ilmiah}

Vol. 13, No. 1, Januari - Juni 2021, P-ISSN 1979-0783, E-ISSN 2655-5042

https://doi.org/10.33322/energi.v13i1.1256

\section{PENDAHULUAN}

Sebagai lembaga pendidikan dan pelatihan di bidang Transmisi Tenaga Listrik dan Pekerjaaan Dalam Keadaan Bertegangan (PDKB) PLN UPDL Semarang sudah menerapkan Sistem Manajemen Keselamatan dan Kesehatan Kerja (SMK3) sejak 2013, sebagai bentuk kepatuhan terhadap Peraturan Pemerintah nomor 50 tahun 2012 [1]. Penerapan SMK3 sendiri dimaksudkan untuk meningkatkan efektifitas dan perlindungan keselamatan dan kesehatan kerja yang terencana, terukur, terstruktur, dan terintegrasi, untuk dapat mencegah dan mengurangi kecelakaan kerja dan penyakit akibat kerja dengan melibatkan unsur manajemen, pekerja atau buruh, dan/atau serikat pekerja/serikat buruh, serta menciptakan tempat kerja yang aman, nyaman, dan efisien untuk mendorong produktifitas [2]. Prinsip dalam penerapan SMK3 ini adalah mengikuti siklus perencanaan (Plan), melaksanakan (Do), Pengendalian (Control), dan tindak lanjut (Act) yang berkelanjutan. Prinsip manajamen ini dikenal dengan prinsip PDCA.

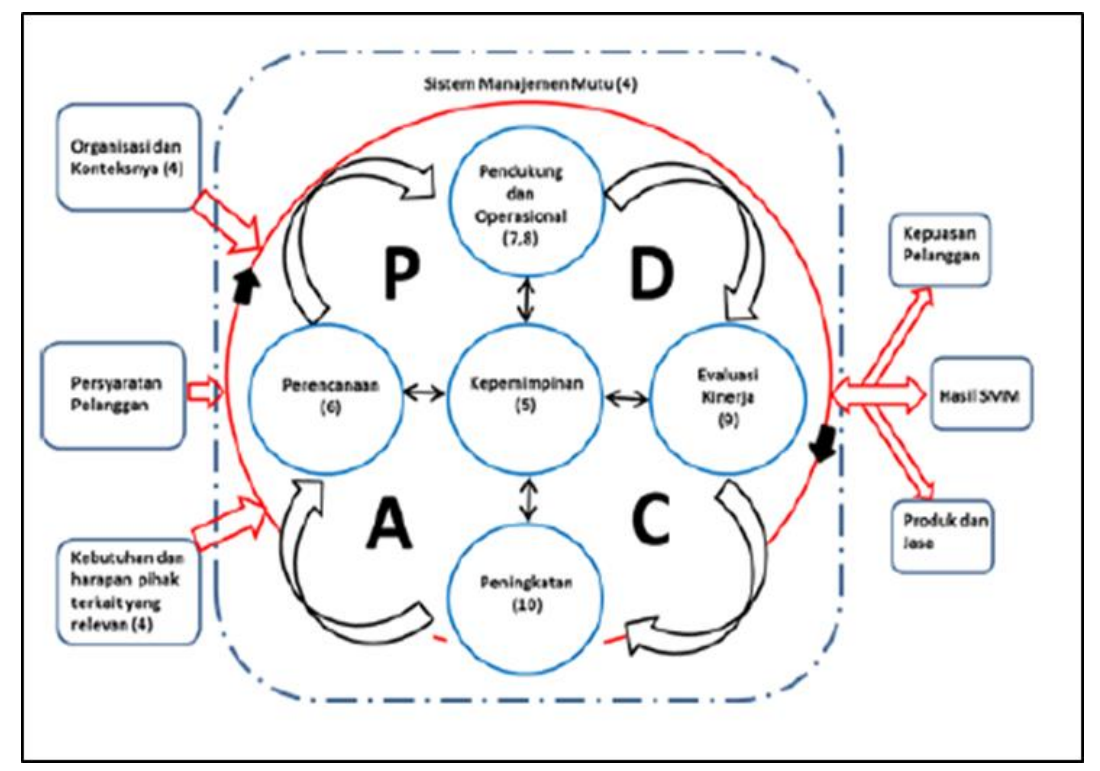

Gambar 1. Prinsip PDCA Sistem Manajemen

Penerapan SMK3 sebagai bagian dari penerapan Sistem Manajemen Terintegrasi di PLN adalah bentuk komitmen Manajemen dan strategi menjalankan roda organisasi/perusahaan yang sistematis, efektif, dan efisien seperti tertuang dalam Keputusan Direksi Nomor 014.K/DIR/2010 [3]. PLN UPDL Semarang sebagai salah satu Unit Pelaksana di PLN yang bertugas menyelenggarakan program pembelajaran menindaklanjuti Keputusan Direksi di atas dengan menyusun Pedoman Pelaksanaan Sistem Manajemen Terintegrasi (SMT) [4]. Beberapa standar yang digunakan dalam SMT itu adalah Sistem Manajemen Mutu (ISO 9001:2015), Sistem Manajemen Lingkungan (ISO 14001:2015), Sistem Manajemen Keselamtan dan Kesehatan Kerja (SMK3) menurut Peraturan Pemerintah Nomor 50 tahun 2012, dan Sistem Manajemen Pengamanan (Peraturan Kepala Kepolisian Republik Indonesia Nomor 24 tahun 2007).

Berkaitan dengan pengendalian dan tindak lanjut, perlu ada upaya pemantauan dari penerapan prorgram-program SMK3, deteksi dini dan upaya pencegahan terjadinya kecelakaan dan penyakit akibat kerja. Selama ini usaha pemantauan dilakukan secara manual dan pencatatan secara konvensional. Dengan berkembangnya teknologi digital di era industri 4.0 seperti sekarang ini, tuntutan kecepatan, keakuratan informasi dan laporan makin tinggi; maka cara-cara manual tidak dapat lagi digunakan. 
Dalam rekayasa perangkat lunak, suatu aplikasi web (bahasa Inggris: web application atau sering disingkat webapp) adalah suatu aplikasi yang diakses menggunakan penjelajah web melalui suatu jaringan seperti internet atau Intranet. Aplikasi web juga merupakan suatu aplikasi perangkat lunak komputer yang dikodekan dalam bahasa yang didukung penjelajah web (Seperti HTML, JavaScript, AJAX, Java, dan lain-lain) dan bergantung pada penjelajah tersebut untuk menampilkan aplikasi [5].

Oleh kerena itu aplikasi Inspekta yang digunakan oleh PLN UPDL Semarang sebagai suatu aplikasi berbasis web ini diharapkan dapat memenuhi tuntutan dan harapan tersebut di atas. Beberapa penelitian sebelumnya tentang penerapan SMK3 di lembaga/instansi atau perusahaan lebih banyak dilakukan dalam bentuk evaluasi secara menyeluruh prinsip-prinsip SMK3 yang tercantum dalam PP 50 tahun 2012 [6]. Pemantauan dan sistem pelaporan kejadian K3 sendiri masih dilakukan secara konvensional, belum menggunakan aplikasi teknologi digital, berbasis web, telepon pintar (smartphone) atau perangkat lunak lainnya serta tidak melibatkan partisipasi orang banyak sebagai wujud awareness/ kepeduliaan di lingkungan organisasi.

Tabel 1. Penelitian terdahulu

\begin{tabular}{|c|c|c|c|c|}
\hline $\begin{array}{c}\text { Peneliti dan } \\
\text { tahun }\end{array}$ & Judul Penelitian & $\begin{array}{c}\text { Obyek } \\
\text { Penelitian }\end{array}$ & $\begin{array}{c}\text { Variabel } \\
\text { Penelitian }\end{array}$ & $\begin{array}{c}\text { Keterangan } \\
\text { (gap analisis) }\end{array}$ \\
\hline $\begin{array}{l}\text { Linchon } \\
\text { Hasiholan } \\
\text { Simorangkir, } \\
\text { Robiana } \\
\text { Modjo }\end{array}$ & $\begin{array}{l}\text { Evaluasi Implementasi } \\
\text { Sistem Manajemen } \\
\text { Keselamatan dan } \\
\text { Kesehatan Kerja untuk } \\
\text { Mencegah Terjadinya } \\
\text { Kecelakaan Kerja di } \\
\text { PT. XYZ Tahun } 2014\end{array}$ & $\begin{array}{l}\text { Evaluasi } \\
\text { penerapan } \\
\text { SMK3 di } \\
\text { Perusahaan }\end{array}$ & $\begin{array}{l}\text { Prinsip-prinsip } \\
\text { Manajemen } \\
\text { SMK3 }\end{array}$ & $\begin{array}{l}\text { - Pemantauan dan } \\
\text { pengendalian dilakukan } \\
\text { secara manual, belum ada } \\
\text { aplikasi yang digunakan. } \\
\text { - Hanya mengukur } \\
\text { keberhasilan penerapan } \\
\text { SMK3 di PT XYZ }\end{array}$ \\
\hline $\begin{array}{l}\text { Fitria } \\
\text { Ciptaningsih* } \\
\text { ), } \\
\text { Ekawati**),Bi } \\
\text { na } \\
\text { Kurniawan**) }\end{array}$ & $\begin{array}{l}\text { Evaluasi Sistem } \\
\text { Manajemen } \\
\text { Keselamatan Dan } \\
\text { Kesehatan Kerja } \\
\text { (SMK3) Di Perusahaan } \\
\text { Industri Baja[6] }\end{array}$ & $\begin{array}{l}\text { Evaluasi } \\
\text { penerapan } \\
\text { SMK3 di } \\
\text { Perusahaan }\end{array}$ & $\begin{array}{l}\text { Prinsip-prinsip } \\
\text { Manajemen } \\
\text { SMK3 }\end{array}$ & $\begin{array}{l}\text { - Pemantauan dan } \\
\text { pengendalian dilakukan } \\
\text { secara manual, belum ada } \\
\text { aplikasi yang digunakan. } \\
\text { - Hanya mengukur } \\
\text { keberhasilan penerapan } \\
\text { SMK3 di Perusahaan } \\
\text { Industri Baja }\end{array}$ \\
\hline $\begin{array}{l}\text { Julia Nujhani, } \\
\text { Ika Juliantina }\end{array}$ & $\begin{array}{l}\text { Evaluasi Penerapan } \\
\text { Sistem Manajmen } \\
\text { Keselamatn Dan } \\
\text { Kesehatan Kerja } \\
\text { (SMK3) Pada Proyek } \\
\text { Persiapan Lahan } \\
\text { PUSRI IIB PT. Pupuk } \\
\text { Sriwidjaja Palembang } \\
\text { [7] }\end{array}$ & $\begin{array}{l}\text { Evaluasi } \\
\text { penerapan } \\
\text { SMK3 pada } \\
\text { Proyek } \\
\text { persiapan lahan }\end{array}$ & $\begin{array}{l}\text { Prinsip-prinsip } \\
\text { Manajemen } \\
\text { SMK3 }\end{array}$ & $\begin{array}{l}\text { - Pemantauan dan } \\
\text { pengendalian dilakukan } \\
\text { secara manual, belum ada } \\
\text { aplikasi yang digunakan. } \\
\text { - Mengukur keberhasilan } \\
\text { penerapan SMK3 di suatu } \\
\text { unit proyek }\end{array}$ \\
\hline $\begin{array}{l}\text { Ardyan } \\
\text { Burhanudin }\end{array}$ & $\begin{array}{l}\text { Evaluasi Penerapan } \\
\text { Sistem Keselamatan } \\
\text { dan Kesehatan Kerja } \\
\text { Pada Area Pet Bottle } 2 \\
\text { (Studi Kasus Pada PT. }\end{array}$ & $\begin{array}{l}\text { Keselamatan } \\
\text { dan Kesehatan } \\
\text { Kerja }\end{array}$ & $\begin{array}{l}\text { Kebisingan,pe } \\
\text { ncahayaan, } \\
\text { panas } \\
\text { lingkungan, } \\
\text { emisi udara, } \\
\text { penggunaan }\end{array}$ & $\begin{array}{l}\text { - Pengukuran terbatas, tidak } \\
\text { melibatkan partisipasi/ } \\
\text { awareness anggota } \\
\text { perusahaan. }\end{array}$ \\
\hline
\end{tabular}




\begin{tabular}{|c|c|c|c|c|}
\hline & $\begin{array}{l}\text { Amerta Indah Otsuka) } \\
\text { [8] }\end{array}$ & & $\begin{array}{l}\text { APD, potensi } \\
\text { bahaya yang } \\
\text { ditimbulkan } \\
\text { dari proses } \\
\text { yang ada di } \\
\text { PET Bottle } 2 \text {. }\end{array}$ & $\begin{array}{l}\text { - Mengevaluasi nilai ambang } \\
\text { batas faktor fisik dan } \\
\text { potensi bahaya }\end{array}$ \\
\hline $\begin{array}{l}\text { Marisca } \\
\text { Imaculata } \\
\text { Firani } \\
\text { Mentang J. } \\
\text { Tjakra, J. E. } \\
\text { Ch. Langi, D. } \\
\text { R. O. } \\
\text { Walangitan }\end{array}$ & $\begin{array}{l}\text { Evaluasi Penerapan } \\
\text { Sistem Manajemen } \\
\text { Keselamatan dan } \\
\text { Kesehatan Kerja Pada } \\
\text { Peningkatan Fasilitas } \\
\text { PT. Trakindo Utama } \\
\text { Balikpapan.[9] }\end{array}$ & $\begin{array}{l}\text { Komitmen dan } \\
\text { Kebijakan; } \\
\text { dikelolanya } \\
\text { divisi K3, } \\
\text { Perencanaan } \\
\text { SMK3, } \\
\text { Penerapan } \\
\text { SMK3, } \\
\text { Pengukuran dan } \\
\text { Evaluasi,Tinjau } \\
\text { an Ulang dan } \\
\text { Peningkatan } \\
\text { oleh Pihak } \\
\text { Manajemen }\end{array}$ & $\begin{array}{l}\text { Prinsip-prinsip } \\
\text { Manajemen } \\
\text { SMK3 } \\
\text { (OHSAS } \\
\text { 18001:2007) }\end{array}$ & $\begin{array}{l}\text { - Pemantauan dan } \\
\text { pengendalian dilakukan } \\
\text { secara manual, belum ada } \\
\text { aplikasi yang digunakan. } \\
\text { - Memahami dan } \\
\text { mengevaluasi penerapan } \\
\text { Sistem Manajemen } \\
\text { Keselamatan dan } \\
\text { Kesehatan Kerja (SMK3) } \\
\text { perusahaan pada } \\
\text { peningkatan fasilitas PT. } \\
\text { Trakindo Utama } \\
\text { Balikpapan. }\end{array}$ \\
\hline
\end{tabular}

Pada penelitian kali ini penulis melakukan evaluasi penerapan SMK3 lebih fokus pada penggunaan aplikasi teknologi yang mendukung sistem pemantauan dan pelaporan potensi bahaya dan kejadian di lingkungan PLN UPDL Semarang. Aplikasi berbasis teknologi informasi yang dibangun PT PLN ini dirancang dalam rangka memenuhi tuntutan era industrialisasi 4.0 yang banyak menggunakan teknologi digital. Aplikasi yang dimaksud adalah bernama Inspekta.

Kondisi Keselamatan, Kesehatan, Kerja dan Lingkungan (K3L) perlu mendapat perhatian dari manajemen selaku Ketua P2K3 dan bentuk komitmen penerapan SMK3 di tempat kerja [10]. Oleh karena itu Manajemen harus melakukan pemantauan, koordinasi dan mengambil keputusan terkait kondisi-kondisi tidak aman/ tidak selamat di lingkungan kerjanya dan berkoordinasi dengan pihakpihak terkait untuk menindaklanjuti temuan untuk mencegah terjadinya kecelakaan kerja. Di era 4.0 yang serba cepat dan informatif ini diperlukan alat bantu untuk memantau, koordinasi sekaligus membangun partisipasi semua karyawan/tenaga kerja untuk peduli terhdap kondisi lingkungan kerja. Monitoring oleh manajer/ketua P2K3 ini juga untuk memastikan agar temuan-temuan yang diunggah oleh pengguna (inspektor), dapat ditangani oleh pihak terkait dan tidak melewati batas waktu (deadline) sesuai setandar SMK3 atau peraturan yang berlaku lainnya [11]. Komunikasi menjadi hal penting untuk mendapat dukungan/ partisipasi karyawan/ tenaga kerja dalam mencapai kinerja K3 dan membangun budaya K3. Dari hasil penelitian sebelumnya komunikasi merupakan salah satu faktor yang mempengaruhi perilaku kerja aman di tempat kerja[12]. Tanpa keterlibatan dan kepedulian tenaga kerja, maka sebagus apapun sistem dan alat yang dibangun, maka budaya K3 yang tidak akan dapat diwujudkan. Kepedulian dan partisipasi karyawan/tenaga kerja adalah salah satu upaya membangun budaya K3 melalui perilaku, kepercayaan, dan nilai yang disepakati secara bersama yang berkenaan dengan K3 [13]. Dengan terbangunnya budaya saling mengingatkan dan memberi informasi, maka pada dasarnya juga sedang membangun perilaku berdasar keselamatan [behavior based safety]. Dari hasil penelitian sebelumnya menunjukkan bahwa keterlibatan pekerja berpengaruh cukup baik dalam membangun budaya K3[14]. 


\section{METODE/PERANCANGAN PENELITIAN}

\subsection{MODEL PENELITIAN}

Aplikasi Inspekta ini dikembangkan PLN sejak 2019. Penyempurnaan-penyempurnaan terus dilakukan, hingga pada Februari 2020 diluncurkan sebagai aplikasi resmi korporat untuk pelaporan implementasi K3, temuan ketidaksesuaian dan melakukan pemantauan tindak lanjut dari temuan ketidaksesuaian. Aplikasi Inspekta dibangun dengan tujuan untuk mendorong seluruh pegawai PLN dalam mengenali potensi bahaya dan tingkat risiko pada setiap aktivitas pekerjaan sehari-hari secara tepat, mendorong Unit PLN terbuka dalam melaporkan inkonsistensi dan ketidaksesuaian implementasi Aspek K3, mendorong Unit PLN berperan aktif dalam menindaklanjuti temuan ketidaksesuaian K3 dan teknis serta memonitor tindak lanjut temuan di lapangan, mendorong Unit PLN dalam mengedepankan Aspek K3 di setiap pengambilan keputusan dan menjadikan hasil pemantauan potensi bahaya dan risiko sebagai lesson learned upaya pencegahan kecelakaan kerja dan kecelakaan instalasi [15].

Secara diagram alir, proses pengisian pada inspekta seperti tampak pada gambar 2 berikut.

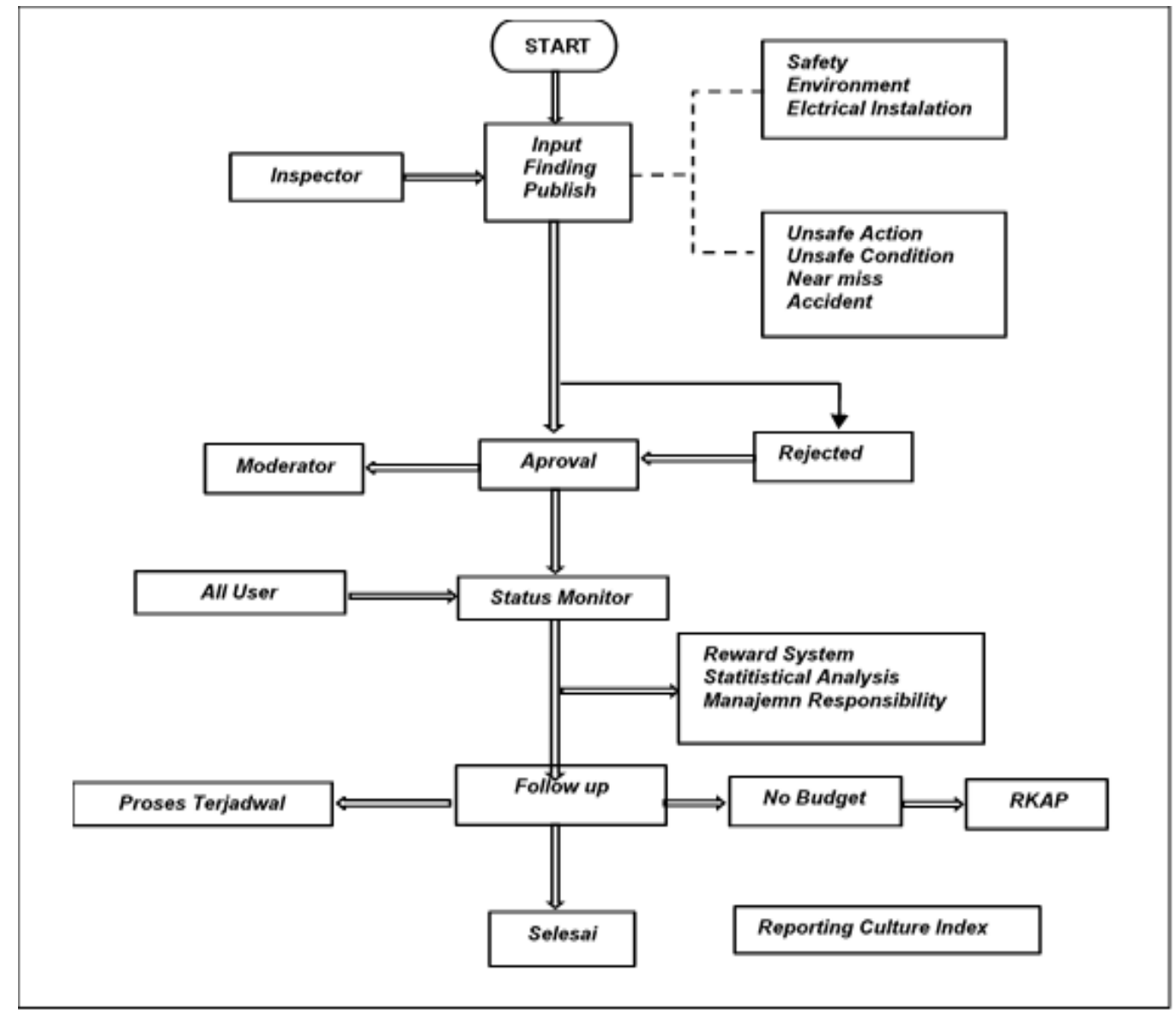

Gambar 2. Flowchart Laporan Inspekta

Dalam aplikasi Inspekta terdapat menu-menu : input temuan, monitoring progres, laporan summary, performance indicator, safety calendar, tanggung jawab saya (penindak lanjut), Maturity level, profil user.

Sebutan-sebutan pengguna (user) dalam aplikasi ini ada admin (pegawai di bidang HSSE di Unit Induk untuk setup data), moderator (pegawai bidang HSSE di unit pelaksana yang bertugas 


\section{Energi dan Kelistrikan: Jurnal Ilmiah}

Vol. 13, No. 1, Januari - Juni 2021, P-ISSN 1979-0783, E-ISSN 2655-5042

https://doi.org/10.33322/energi.v13i1.1256

penyaring/filter informasi), inspector (semua pegawai pelapor temuan), executive observer (manajemen yang memonitor tindak lanjut)

Semua pegawai PLN dapat berpartispasi dalam memantau dan mengidentifikasi potensi bahaya//kejadian di tempat kerja terkait K3 dan melaporkannya melalui aplikasi ini. Untuk akses ke aplikasi ini pegawai cukup menggunakan username dan password akun email korporat masingmasing pegawai ke portal https://hsse.pln.co.id/. Pegawai yang mengisi laporan disebut sebagai inspektor. Selanjutnya inspektor mengisi formulir yang sudah tersedia dan menentukan kategori temuannya apakah berkaitan safety, environment, atau electrical instalation. Pada form dalam inspekta juga teresedia kolom dokumentasi foto temuan. Masing-masing kategori ditentukan kondisi bahayanya apakah unsafe action (tindakan tidak aman), unsafe condition (kondisi tidak aman), near miss (hampir celaka), atau accident (kecelakaan). Pihak moderator dalam hal ini penanggung jawab K3L (Keselamatan Kesehatan Kerja dan Lingkungan) di unit masing-masing akan memberikan persetujuan (approval) atau penolakan (reject) agar ada kepastian status temuan. Jika temuan diterima (approved), maka akan diteruskan ke bagian/ pihak terkait untuk ditindak lanjuti (follow up) sampai dinyatakan selesai (closed). Untuk setiap temuan akan diberikan poin penghargaan secara sistem kepada inspektor

\subsection{METODE PENELITIAN}

Penulis melakukan pengumpulan data dengan metode triangulasi, yaitu dengan cara menggambungkan hasil observasi, wawancara, dan dokumen berbagai sumber. Observasi dilakukan melalui pengamatan terhadap obyek penelitian dan melakukan akses terhadap aplikasi Inspekta. Untuk mengetahui lebih mendalam tentang penggunaan aplikasi Inspekta dan melengkapi data penelitian juga dilakukan wawancara terhadap Pejabat K3L sebagai penanggung jawab penerapan K3L di PLN UPDL Semarang. Penulis juga melakukan analisis dan evaluasi terhadap dokumen/laporan yang tersaji dari aplikasi Inspekta [16]. Dari hasil triangulasi ini ditarik kesimpulan dan peluang-peluang perbaikan dari penerapan aplikasi Inspekta. Teknik Triangulasi data terlihat pada gambar (3) dan model tampilan menu aplikasi Inspekta seperti terlihat pada gambar (4) di bawah ini.

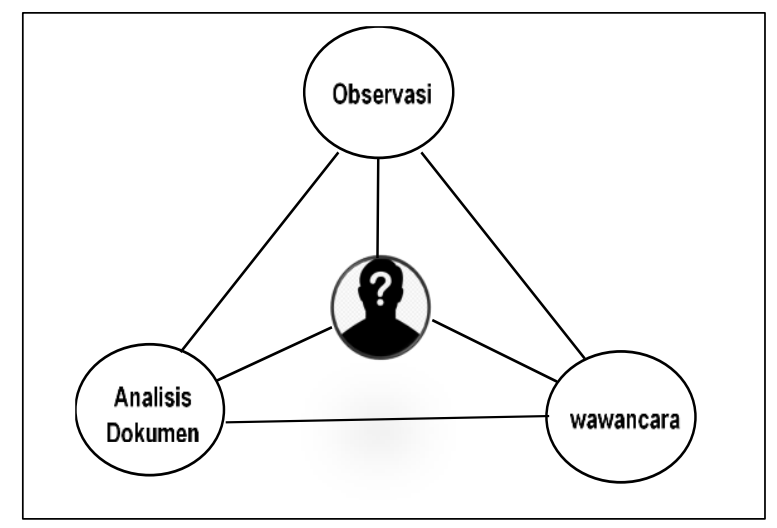

Gambar 3. Teknik Tringulasi Analisis Data 


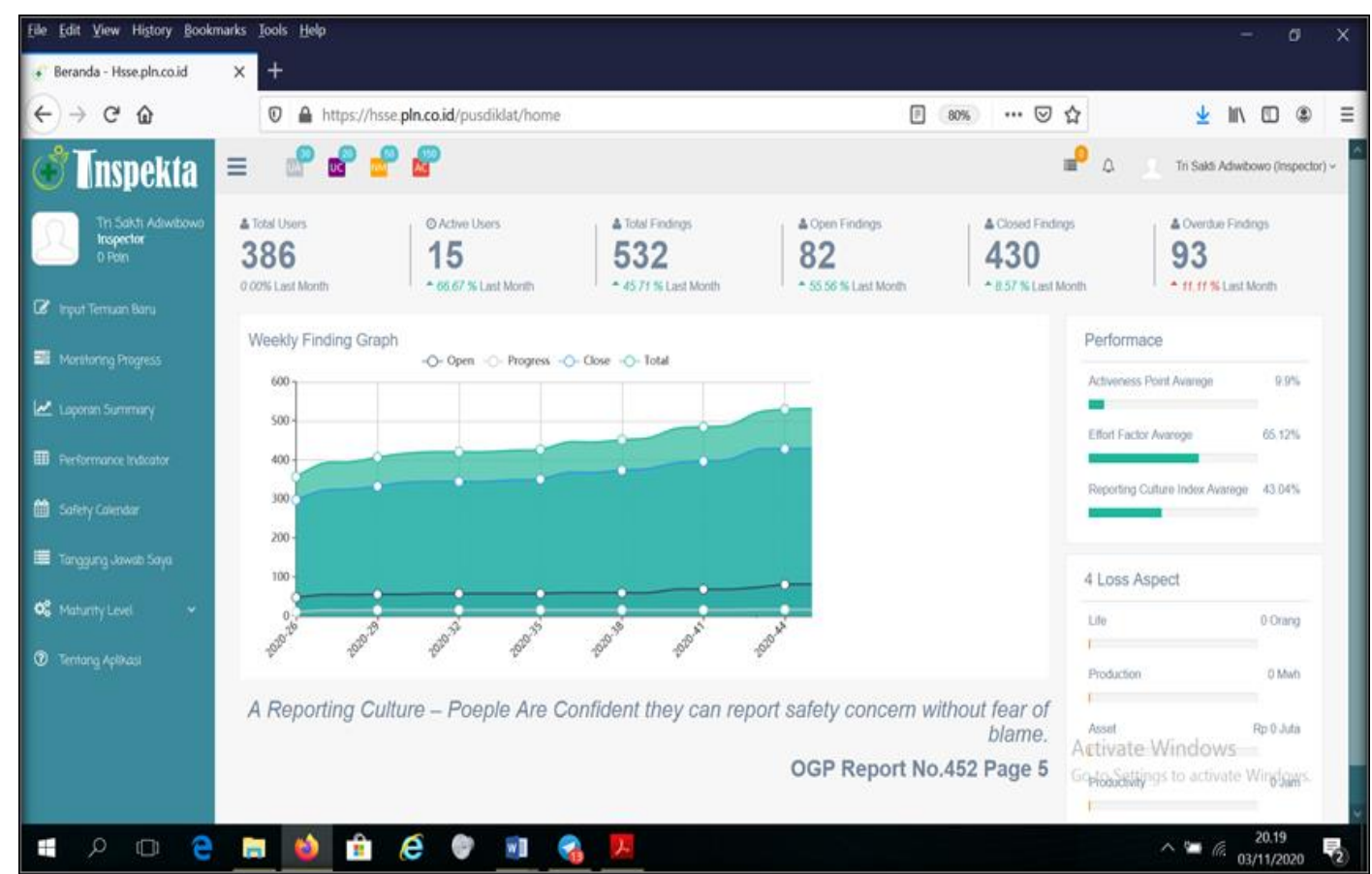

Gambar 4. Tampilan Menu Aplikasi Inspekta

\section{HASIL DAN PEMBAHASAN}

Dari akses aplikasi Inspekta yang dapat diambil untuk dipelajari adalah catatan temuantemuan yang dimasukan oleh inspektor, kategori temuan, tanggal dimasukan, tindak lanjut temuan, dan status temuan seperti tergambarkan dalam tabel 2.

Aplikasi Inspekta telah membantu Pengelola K3L melakukan pemantauan dan perekaman secara tersistematis, terstruktur, dan dapat dipertanggungjawabkan. Hal ini akan mendukung konsistensi penerapan SMK3 di PLN UPDL Semarang dan pencapaian Kinerja K3L. Temuantemuan terkait K3 yang terjadi di lingkungan UPDL Semarang sejak awal tahun 2020 tercatat ada 16 temuan yang didominasi oleh temuan kategori kondisi tidak aman (unsafe condition). Dari 16 temuan kondisi tidak aman ini, 6 temuan termasuk jenis temuan lingkungan (environment), sedang 10 lainnya termasuk dalam jenis temuan keselamatan (safety). Dari laporan temuan di aplikasi Inspekta juga sudah tercantum saran tindak lanjut yang harus dilaksanakan pihak terkait.

Sampai batas waktu deadline yang ditetapkan dari 16 temuan 2020 yang sudah terekam, sebanyak 8 temuan (50\%) sudah ditindak lanjuti atau dinyatakan selesai (closed), sementara 50\% lainnya belum selesai atau statusnya masih terbuka (open), bahkan melewati batas waktu (deadline) yang tercantum. Standarisasi waktu temuan yang mengacu Peraturan Pemerintah Nomor 50 tahun 2012 dan peraturan lainnya yang terkait belum diterapkan, sehingga memungkinkan status temuan akan terbuka (open) tanpa batas waktu tindak lanjut. Rekaman Inspekta belum menunjukan adanya keterlibatan pihak-pihak lain atau partisipasi para anggota perusahaan keseluruhan. Pejabat pengelola K3 masih mendominasi sebagai inspektor sekaligus moderator dalam aplikasi ini. Meskipun semua anggota perusahaan [pegawai] di lingkungan PLN UPDL Semarang sudah dimasukan namanya sebagai inspektor dalam aplikasi Inspekta. 
Energi dan Kelistrikan: Jurnal Ilmiah

Vol. 13, No. 1, Januari - Juni 2021, P-ISSN 1979-0783, E-ISSN 2655-5042

https://doi.org/10.33322/energi.v13i1.1256

Tabel 2. Rekaman Hasil Pemantauan Inspekta

\begin{tabular}{|c|c|c|c|c|c|}
\hline Kondisi & $\begin{array}{c}\text { Tanggal } \\
\text { input }\end{array}$ & Kategori & Pelapor & Tindak lanjut & Status \\
\hline $\begin{array}{l}\text { Adanya bola lampu } \\
\text { tidak pada tempatnya } \\
\text { (TPS Limbah B3 [E]* }\end{array}$ & $\begin{array}{l}31 \text { August } \\
2020\end{array}$ & $\begin{array}{l}\text { Unsafe } \\
\text { Condition }\end{array}$ & Dwi Basuki N & $\begin{array}{l}\text { Memindahkan bola } \\
\text { lampu yang tidak } \\
\text { terpakai ke TPS Limbah } \\
\text { B }\end{array}$ & Closed \\
\hline $\begin{array}{l}\text { Adanya hydrant yang } \\
\text { terhalang oleh barang- } \\
\text { barang }[\mathrm{S}]^{* *}\end{array}$ & $\begin{array}{c}30 \\
\text { September } \\
2020\end{array}$ & $\begin{array}{l}\text { Unsafe } \\
\text { Condition }\end{array}$ & Dwi Basuki N & $\begin{array}{lr}\text { Segera } & \text { lakukan } \\
\text { pemindahan terhadap } \\
\text { barang-barang } \\
\text { menghalangi hydrant }\end{array}$ & Closed \\
\hline $\begin{array}{l}\text { Adanya tanah tergerus } \\
\text { pada bangunan/gedung } \\
{[\mathrm{S}]^{* *}}\end{array}$ & $\begin{array}{c}27 \\
\text { Oktober } \\
2020\end{array}$ & $\begin{array}{c}\text { Unsafe } \\
\text { Condition }\end{array}$ & Dwi Basuki N & $\begin{array}{l}\text { Melakukan perbaikan } \\
\text { pada tanah yang } \\
\text { tergerus/memperbaiki } \\
\text { pondasi bangunan }\end{array}$ & Closed \\
\hline $\begin{array}{l}\text { Adanya tampilan } \\
\text { CCTV terbalik }[\mathrm{S}]^{* *}\end{array}$ & $\begin{array}{c}27 \\
\text { Oktober } \\
2020\end{array}$ & $\begin{array}{c}\text { Unsafe } \\
\text { Condition }\end{array}$ & Dwi Basuki N & $\begin{array}{l}\text { Melakukan perbaikan } \\
\text { pada tampilan CCT }\end{array}$ & Closed \\
\hline $\begin{array}{l}\text { Adanya tampilan } \\
\text { CCTV tidak } \\
\text { terlihat/kamera rusak } \\
{[\mathrm{S}]^{* *}}\end{array}$ & $\begin{array}{c}27 \\
\text { Oktober } \\
2020\end{array}$ & $\begin{array}{l}\text { Unsafe } \\
\text { Condition }\end{array}$ & Dwi Basuki N & $\begin{array}{l}\text { Dilakukan } \begin{array}{r}\text { perbaikan } \\
\text { atau penggantian } \\
\text { terhadap kamera yang } \\
\text { rusak }\end{array} \\
\end{array}$ & Closed \\
\hline $\begin{array}{l}\text { Adanya tampilan } \\
\text { CCTV yang tidak } \\
\text { terlihat }[\mathrm{S}]^{* *}\end{array}$ & $\begin{array}{c}27 \\
\text { Oktober } \\
2020\end{array}$ & $\begin{array}{c}\text { Unsafe } \\
\text { Condition }\end{array}$ & Dwi Basuki N & $\begin{array}{l}\text { Dilakukan perbaikan } \\
\text { atau pemeliharaan } \\
\text { terhadap CCTV tersebut }\end{array}$ & Closed \\
\hline $\begin{array}{l}\text { Adanya ceceran air } \\
\text { dilantai gedung graha } \\
\text { supriyo }[\mathrm{S}]^{* *}\end{array}$ & $\begin{array}{l}9 \text { Februari } \\
2021\end{array}$ & $\begin{array}{l}\text { Unsafe } \\
\text { Condition }\end{array}$ & Dwi Basuki N & $\begin{array}{l}\text { Membersihkan ceceran } \\
\text { air yang ada di lantai } \\
\text { gedung graha supriyo }\end{array}$ & Closed \\
\hline $\begin{array}{l}\text { Adanya kabel terbuka } \\
\text { di eks box KWH }[\mathrm{S}]^{* *}\end{array}$ & $\begin{array}{l}31 \text { Mei } \\
2021\end{array}$ & $\begin{array}{l}\text { Unsafe } \\
\text { Condition }\end{array}$ & Dwi Basuki N & $\begin{array}{l}\text { agar dilakukan } \\
\text { pengamanan/penutupan } \\
\text { terhadap kabel terbuka }\end{array}$ & Open \\
\hline $\begin{array}{l}\text { Adanya saklar tidak } \\
\text { menempel di tembok } \\
{[\mathrm{S}]^{* *}}\end{array}$ & $\begin{array}{c}23 \\
\text { Desember } \\
2020\end{array}$ & $\begin{array}{l}\text { Unsafe } \\
\text { Condition }\end{array}$ & Dwi Basuki N & $\begin{array}{l}\text { Menempelkan ke } \\
\text { tembok saklar yang lepas }\end{array}$ & Closed \\
\hline
\end{tabular}

Tabel 3. Optimalisasi Fitur/ Menu Inspekta

\begin{tabular}{|l|l|l|l|l|}
\hline \multicolumn{1}{|c|}{$\begin{array}{c}\text { Nama } \\
\text { Fitur/Menu }\end{array}$} & \multicolumn{1}{|c|}{ Fungsi } & \multicolumn{1}{|c|}{ Kondisi eksisting } & $\begin{array}{c}\text { Peluang Perbaikan/ } \\
\text { pengembangan }\end{array}$ & \multicolumn{1}{|c|}{ Keterangan } \\
\hline $\begin{array}{l}\text { Pilihan } \\
\text { Jenis } \\
\text { temuan }\end{array}$ & Kategori K3 & $\begin{array}{l}\text { Safety, Environement, } \\
\text { Instalasi } \\
\text { Ketengalistrikan }\end{array}$ & $\begin{array}{l}\text { Tambahan Katageori } \\
\text { kesehatan }\end{array}$ & Sesuai definisi K3 \\
\hline $\begin{array}{l}\text { Input } \\
\text { Maturity } \\
\text { Level }\end{array}$ & $\begin{array}{l}\text { Mengetahui } \\
\text { pencapaian } \\
\text { level maturity }\end{array}$ & Belum ada data & Pengisian data & Indikator Maturity \\
\hline $\begin{array}{l}\text { About } \\
\text { Inspekta }\end{array}$ & $\begin{array}{l}\text { Memberi } \\
\text { pedoman } \\
\text { pemakaian user }\end{array}$ & Belum terisi & $\begin{array}{l}\text { Menjelaskan tentang } \\
\text { aplikasi \& panduan } \\
\text { pemakaian }\end{array}$ & $\begin{array}{l}\text { Informasi dan } \\
\text { pedoman } \\
\text { pemakaian }\end{array}$ \\
\hline
\end{tabular}


Energi dan Kelistrikan: Jurnal Ilmiah

Vol. 13, No. 1, Januari - Juni 2021, P-ISSN 1979-0783, E-ISSN 2655-5042 https://doi.org/10.33322/energi.v13i1.1256

\begin{tabular}{|l|l|l|l|l|}
\hline & $\begin{array}{l}\text { Monitoring } \\
\text { Manajemen }\end{array}$ & Belum terlihat & Ditambahkan & $\begin{array}{l}\text { Bentuk Komitmen } \\
\text { Manajemen }\end{array}$ \\
\hline $\begin{array}{l}\text { Notifikasi } \\
\text { ke bidang } \\
\text { terkait }\end{array}$ & $\begin{array}{l}\text { Pemberitahuan } \\
\text { ke pihak terkait } \\
\text { untuk tindak } \\
\text { lanjut }\end{array}$ & $\begin{array}{l}\text { Pihak terkait mengetahui } \\
\text { permintaan tindak lanjut } \\
\text { jika membuka aplikasi } \\
\text { atau pembritahuan dari } \\
\text { moderator. }\end{array}$ & $\begin{array}{l}\text { Ada notifikasi khusus } \\
\text { ke pihak terkait } \\
\text { sebagai } \\
\text { pemberitahuan. }\end{array}$ & $\begin{array}{l}\text { Sebagai reminder } \\
\text { penanggungjawab } \\
\text { tindak lanjut }\end{array}$ \\
\hline & $\begin{array}{l}\text { Batas waktu } \\
\text { deadline }\end{array}$ & $\begin{array}{l}\text { Belum ada standar } \\
\text { deadline [batas waktu] } \\
\text { tindak lanjut temuan } \\
\text { Inspekta }\end{array}$ & $\begin{array}{l}\text { Ada standarisasi batas } \\
\text { waktu penyelesaian }\end{array}$ & $\begin{array}{l}\text { Untuk } \\
\text { memudahkan } \\
\text { monitoring \& } \\
\text { pengendalian }\end{array}$ \\
\hline
\end{tabular}

Dari hasil penggunaan aplikasi Inspekta yang sudah diluncurkan awal tahun 2020 ini di PLN Pusdiklat, masih ada beberapa hal yang perlu dilakukan optimalisasi terhadap aplikasi dan peran dari anggota perusahaan dalam meningkatkan maturity level K3 seperti tercantum pada tabel 3 di atas. Sesuai definisi Keselamatan dan Kesehatan Kerja (K3), maka upaya-upaya pencegahan tidak hanya terkait keselamatan saja tapi potensi-potensi timbulnya Penyakit Akibat Kerja (PAK) dan Penyakit Akibat Hubungan Kerja (PAHK) di lingkungan tempat kerja juga perlu diantisipasi. Sehingga pilihan jenis temuan akan lebih sempurna apabila ditambahkan kategori pemantauan kesehatan kerja, apalagi saat ini pandemi sedang melanda seluruh dunia.

Pada menu input Maturity Level $(M L)$ belum diisi angkanya, sehingga belum dapat mengukur sejauh mana tingkat kematangan penerapan K3 di unit-unit di lingkungan PLN Pusdiklat. Angka Maturity level ini akan memberi informasi dan memacu unit-unit di lingkungan PLN Pusdiklat untuk melakukan upaya-upaya perbaikan yang berkesinambungan sehingga masalah Keselamatn dan Kesehatan Kerja menjadi kepedulian semua pihak, tidak hanya petugas pengelola K3L.

Menu about inspekta belum ada isinya, sehingga tidak memberi informasi yang cukup bagi pengguna (user) baru tentang aplikasi Inspekta dan cara penggunaannya. Pengguna harus menghubungi pihak pengelola terlebih dahulu untuk mengetahui cara penggunaannya.

Kondisi K3L perlu mendapat perhatian dari manajemen unit setempat, memgingat tanggung jawabnya sebagai Ketua P2K3 dan bentuk komitmen penerapan SMK3 di tempat kerja. Oleh karena itu aplikasi monitoring ini juga sebaiknya ada fungi monitoring terhadap temuan dan tindak lanjutnya oleh Manajemen. Sehingga Kendala-kendala yang mungkin tidak dapat diatasi oleh petugas pelaksana dapat segera dieksekusi setelah ada keputusan oleh manajer. Monitoring oleh manajer/ketua P2K3 ini juga untuk memastikan agar temuan-temuan yang diunggah oleh pengguna (inspektor), dapat ditangani oleh pihak terkait dan tidak melewati batas waktu (deadline). Batas waktu pun belum ada standar baku yang dapat menjadi acuan semua pihak, masih bersifat subyektif moderator, sehingga belum terukur dengan baik. Akan lebih baik jika setiap temuan ada kategori ringan [minor], sedang [mayor], berat [krtitikal], mengacu pada pada setandar SMK3 atau peraturan yang berlaku lainnya dan batas waktu penyelesaian.

Partisipasi dari pegawai dalam penggunaan aplikasi ini masih rendah. Dari 40 pegawai terdaftar, yang aktif mengisi laporan ini masih dilakukan oleh pejabat K3L sendiri, sebagai inspektor sekaligus moderator, atau tingkat partisipasi baru mencapai 2,5\%. Hal ini tentu tidak sesuai sasaran yang diharapkan. Aplikasi ini sebenarnya alat untuk mendorong partisipasi, keterlibatan, dan kepedulian (awareness) banyak pihak, sehingga tingkat kematangan (Maturity Level) penerapan K3 ini menjadi maksimal. Tingkat kematangan penerapan K3 berturut-turut dari mulai yang terendah adalah adalah reactif (dijalankankan berdasar naluri alamiah, dependent (sudah ada komitmen manajemen dan ada supervisi yang mengarahkan dan mengawasi K3), independent (sudah menjadi 


\section{Energi dan Kelistrikan: Jurnal Ilmiah}

Vol. 13, No. 1, Januari - Juni 2021, P-ISSN 1979-0783, E-ISSN 2655-5042

https://doi.org/10.33322/energi.v13i1.1256

kebutuhan individu), interdependent (ada budaya saling mengingatkan dan kepedulian antar individu). Jika tingkat kematangan sudah mencapai interdependent, maka sasaran nihil kecelakan atau Zero Accident lebih mudah terwujudkan. Dengan menggunakan aplikasi ini budaya peduli, saling mengingatkan dengan mendorong keterlibatan semua pekerja di lingkungan perusahaan terhadap kondisi dan perilaku selamat dan sehat akan membentuk budaya (health \& safety culture).

Belum maksimalnya penggunaan aplikasi Inspekta ini, karena belum disosialisasikannya Inspekta secara massif kepada semua pekerja yang ada di lingkungan UPDL Semarang. Oleh karena itu sosialisasi tentang aplikasi pemantauan Keselamatan dan Kesehatan Kerja serta Lingkungan ini menjadi penting untuk dapat dilakukan dengan segera.

\section{KESIMPULAN DAN SARAN}

Aplikasi Inspekta telah membantu pekerjaan pemantauan dan pelaporan potensi bahaya dan kejadian di lingkungan PLN UPDL Semarang. Meskipun masih berbasis website, aplikasi yang dibangun PLN ini cukup mudah pemakaiannya (user-friendly) karena fitur-fiturnya sudah banyak menggunakan bahasa Indonesia. Aplikasi ini juga mendukung perekaman (dokumentasi) kejadian terkait K3 dan tingkat Maturity Level yang diperlukan sebagai dasar perbaikan berkelanjutan dalam penerapan SMK3 dan menunjang kinerja K3 Perusahaan.

Namun demikian aplikasi ini masih perlu dioptimalkan dan dikembangkan lagi. Beberapa fitur masih bias dikembangkan dan dimanfaatkan secara maksimal sebagai sumber informasi K3, mendorong partisipasi semua pegawai untuk peduli terhadap K3, lingkup pemantauan lebih luas tidak hanya terbatas pada potensi kecelakaan kerja tapi juga potensi bahaya penyakit akibat kerja. Untuk itu perlu dilakukan sosialisasi penggunaan aplikasi Inspekta kepada semua pegawai dan kepedulian (awarenss) terhadap potensi bahaya K3.

Ke depan diharapkan Aplikasi Inspekta bisa dibangun berbasis telepon pintar (smartphone), sehingga setiap pekerja dapat langsung memasukan kondisi/perilaku tidak aman/sehat/bahaya, kejadian kecelakaan, dan kondisi lingkungan yang dilihatnya ke dalam aplikasi di telepon genggamnya masing-masing lengkap dengan foto dan posisi kejadian berdasar Global Positioning System (GPS) dengan lebih cepat dan akurat.

\section{DAFTAR PUSTAKA}

[1] Presiden Reuplik Indonesia, Peraturan Pemerintah Republik Indonesia Nomor 50 Tahun 2012 Tentang Penerapan Sistem Manajemen Keselamatan Dan Kesehatan Kerja. 2012, pp. 1-80.

[2] L. H. Simorangkir and R. Modjo, "Evaluasi Implementasi Sistem Manajemen Keselamatan Dan Kesehatan Kerja Untuk Mencegah Terjadinya Kecelakaan Kerja di PT. XYZ Tahun 2014," 2014.

[3] Dahlan Iskan, "Keputusan Direksi PT. PLN (Persero) Nomor:014.K/DIR/2010 Tentang Pedoman Pelaksanaan PLN Management System (PLN-MS) Di Lingkungan PT PLN (Persero)," 014.K/DIR/2010, 2010.

[4] PLN Pusdiklat, "Pedoman Sistem Manajemen Terintegrasi," PSMT.01.01, 2017.

[5] M. Zia'ulhaq, "Penerapan Sistem Informasi Berbasis Web Untuk Mendukung Pengelolaan Administrasi di Promusic Recording Studio Jepara," Siadin.Dinus.Ac.Id, pp. 1-10, 2014.

[6] F. Ciptaningsih, Ekawati, and B. Kurniawan, "Evaluasi Sistem Manajemen Keselamatan Dan Kesehatan Kerja (SMK3) Di Perusahaan Industri Baja,” J. Kesehat. Masy., vol. 2, no. 4, pp. 259-266, 2014. 
[7] I. J. Jula Nujhani, "Evaluasi Penerapan Sistem Manajemen Keselamatn dan Kesehatan Kerja (SMK3) Pada Proyek Persiapan Lahan Pusri IIB PT. Pupuk Sriwidjaja Palembang," J. Tek. Sipil dan Lingkung., vol. 1, no. 1, pp. 80-85, 2013.

[8] A. Burhanudin, "Evaluasi Penerapan Sistem Keselamatan Dan Kesehatan Kerja Pada Area Pet Bottle 2 (Studi Kasus Pada PT Amerta Indah Otsuka),” vol. 2, 2016.

[9] D. R. O. W. Marisca Imaculata Firani Mentang, J. Tjakra, J.E. Ch. Langi, "Evaluasi Penerapan Sistem Manajemen Keselamatan dan Kesehatan Kerja pada Peningkatan Fasilitas PT. Trakindo Utama Balikpapan," J. Sipil Statik, vol. 1, no. 5, pp. 318-327, 2013.

[10] E. Atikah, Ida Wahyuni, “Analisis Komitmen Pimpinan Terhadap Kesiapan Penerapan Sistem Manajemen K3 Pada Salah Satu Fakultas Kesehatan Masyarakat Di Indonesia,” J. Kesehat. Masy., vol. 4, no. 4, pp. 645-651, 2016.

[11] M. Hanif Dhakiri, Peraturan Menteri Ketenagakerjaan Republik Indonesia Nomor 26 Tahun 2014 Tentang Penyelenggaraan Penilaian Penerapan Sistem Manajemen Keselamatan dan Kesehatan Kerja. Indonesia, 2014.

[12] N. Susanto, W. Budiawan, R. Purwaningsih, and D. R. Sabrina, "Implementasi Perbaikan Perilaku Kerja Aman Menggunakan Pendekatan Behavior-Based Safety pada Industri Batik di Kota Semarang," J. Ergon. dan K3, vol. 4, no. 1, pp. 16-23, 2019, doi: 10.5614/j.ergo.2019.4.1.3.

[13] S. H. Alidina Nur Afifah, "Analisis Budaya K3 dengan Nordic Occupational Safety Climate Questionnaire dan Safety Culture Maturity Model," Kes Mas J. Fak. Kesehat. Masy., vol. 12, no. 2, pp. 113-119, 2018, doi: 10.12928/kesmas.v12i2.9259.

[14] E. D. N. Karina Zain Suyono, "Hubungan Antara Faktor Pembentuk Budaya Keselamatan Kerja Dengan Safety Behavior di PT DOK dan Perkapalan Surabaya Unit Hull Construction," Indones. J. Occup. Saf. Heal., vol. 2, no. 1, pp. 67-74, 2013.

[15] PT PLN (Persero), Panduan Aplikasi Inspekta. Jakarta1, Indonesia: PT PLN Persero, 2020.

[16] I. M. L. M. Jaya, Metode Penelitian Kuantitatif dan Kualitatif, Pertama. Yogyakarta: Penerbit Quadrant, 2020. 